\title{
The Postmodern Curriculum in a Modern Classroom
}

\author{
Marius Boboc \\ Dept. of Curriculum \& Foundations, Cleveland State University \\ 2485 Euclid Ave., JH 382, Cleveland, OH 44115, U.S.A \\ Tel: 1-216-687-4581_E-mail: m.boboc@csuohio.edu
}

Received: December 13, 2011 Accepted: January 30, 2012 Published: March 1, 2012

doi:10.5296/ije.v4i1.1167ＵRL: http://dx.doi.org/10.5296/ije.v4i1.1167

\begin{abstract}
This article is intended to formulate several points of interest in the study of various forms postmodern curricula take in our contemporary classrooms. A critical look at the state of the latter poses the question of accommodating the needs of an increasingly diverse student population. The answer lies in curriculum negotiations (Hyun, 2006) representing sustainable adaptability. However, in an era of accountability that prescribes the structure and sequence of curriculum, our schools (perceived as a social system) lag behind. Therefore, the connection our students develop among truth, knowledge, value, and their own petits récits - personal texts that weave the web of their public lives in and outside of schools represents the focus of future research into effective design, implementation, and evaluation of inclusive and student-centered curricula.
\end{abstract}

Keywords: Curriculum, Postmodernism, Education 


\section{Introduction: Postmodernism vs. modernism - points of (dis)juncture}

Postmodernism is a contrast it modernist ideas of "new" - a new epoch, a new socio-economic order, thus, for some representing a continuation of modernism, while for others a 'breaking away' from it. Historic periodization is modernist, while Foucault (1980) conceives of modernity and postmodernity as "oppositional attitudes" that coexist at any given time. When historical eras acquire self-awareness, they enter a new stage in their existence - the "post"period of a previous status quo. For Matei Calinescu (1987), modernity, rather bourgeois in its definition, is characterized by progress spurred by the advances of science and technology, under the auspices of time that is a commodity. At the same time, reason and pragmatism support the "ideal of freedom defined within the framework of an abstract humanism" (p. 44). Everything can be known, defined, analyzed, classified, thus quantified and reduced to a piece in the puzzle of human knowledge. The test of time (i.e., usability, replicability, or what Lyotard calls "performativity") will tell whether specific elements of acquired knowledge are worth "circulating" to expand gnosis or they should be cast into oblivion, thus operationalizing truth. This new knowledge will be discarded as "not marketable" if it does not lead to improving one's personal and/or professional status or if it does not represent a means to a definite end in the informational exchange. Under these circumstances, the points of (dis)juncture between postmodernism and modernism carry over into every conversation about education in the $21^{\text {st }}$ century that attempts to identify optimal parameters of teaching, learning, and assessment in a world getting more diverse.

Lyotard's (1984) notion of metanarratives uses language to reveal Truth, thus promoting Reason in a rational, replicable way that develops specifically the kind of gnosis that humankind needs in its quest for certainty. This foundationalist, rationalist perspective thrives on the grands récits passed down as tradition from immemorial times, whose message resonates in the work of thinkers such as Descartes, Locke, Voltaire or Kant. The modern individual has to be certain that his/her own knowledge is solidly grounded in the immediate reality. These metanarratives, perpetrated by what Wittgenstein (1953) calls "language games", speak of a testable reality that is not delusory. Its very existence allows for the technological advents that can only deepen the modern person's knowledge of their reality this is the complete cycle that Modernism promotes.

Giroux (1992) mentions the rigid, unalterable boundaries of the modernist cultural frame that excludes categories such as race, class, gender, and ethnicity, thus reproducing "relations of domination, subordination, and inequality" (p. 54). Moreover, the meaning of all the modernist language games is profoundly affected by the dichotomy "one" vs. "other." Peters (1995) emphasizes the prohibitive, restrictive tendency of modernity to conceal the possibility of other meanings, as initiated by the "unauthorized others" from the proper functioning of mainstreaming discourses. Giroux (1992) focuses specifically on such mainstreaming discourses as revealing a language of binary oppositions that establish practices and pass on customs reproducing biased assumptions and ethnocentric approaches. The vast majority of those alike share certain inherent and/or acquired characteristics that help them to conform with the socially accepted norms related to truth, reason, language, the 
self vs. the other, power, creativity, and the aesthetic. Under these circumstances, which characteristics (or credentials) should the "other" promote when competing with the majority? Wouldn't the label "other" disqualify/demote its bearers to lesser worth, in contrast with the social value promoted by the tradition and "legitimate knowledge" (Eisner, 2001, pp. 64-65) circulated by the majority? Answers to such questions have led to the identification of certain issues unresolved by the straightforward approach of modernism to power, patriarchy, authority, identity, ethics, (re)production of cultural patterns, linguistic alterations, all within the consecrated dominant discourse.

Postmodernism is a combination of any of the following, at any given time: a state of affairs; an explanatory set of ideas; and an artistic style (Ward, 2003). Unlike any other period preceding it, postmodernism is highly reflective, acutely aware of its confounding mix of features in an endless array of possibilities. The never ending, limitless and all-encompassing state of affairs could possibly use any ideas to justify itself in a constantly recreating artistic style, in a world without pre-set references that could jeopardize fast-paced change verging on instability (Usher and Edwards, 1994). All this sort of constructive turbulence represents a "mutating mixture of risks and excitements, losses and gains, resulting from the destruction of the old and creation of the new" (Best and Kellner, 1997, p. 15).

Giroux (1992) considers postmodernism an age thriving on plurality, difference and multiple narratives that constantly regenerate and recharge themselves, that can be both expressed and professed. Other postmodern challenges to modernity include shifting identities, remapping borders, and non-synchronous memory. The relationship between culture and power has been altered due to the greatly increased access to knowledge around the clock and irrespective of location by means of technology. The new ways of reading history allow for a reconfiguration of the center/margin hierarchies, made possible by the blurring of the previous distinction between high and low (or popular) culture (Usher and Edwards, 1994). However, the displacement of the old postcolonial literature by the myriad of multicultural products of the pop culture has led to the McDonaldization of cultural exports (Ritzer, 2000). Popular culture's effect on contestation, struggle, resistance, and self-affirmation within cultural (re)creation can be perceived as an extension of the revolution of the "other" within the confines of the former modernity: "the Third World has exploded into the metropolis" (Giroux, 1992, p. 58).

Postmodern individuals have to live in a world governed by overwhelming, non-stop communication, which is a constant informational revolution with no preset aims. They find themselves in competition with their own virtual reflection in a hyper-reality created to fill in the ever-growing gap that has been distancing them from other fellow humans. Consequently, all standards have become either obsolete or irrelevant to new generations because of the constant search for gratification of one's own self-regenerating pleasures "unconstrained by a hierarchy of foundational and transcendental reason and values" (Usher and Edwards, 1994, p. 11). In an unprecedented manner, popular culture supports postmodernism's resistance toward metanarratives (Peters, 1998). Concurrently, it brings together truth, reason, and language at the micro-level of the individual, validating her/his petit récit in a non-formulaic way that validates its belonging to a culture of a constantly 
evolving "other," while making it stand apart from any other discourse.

\section{Background: The postmodern individual}

The relationships among the postmodern individual, knowledge, and societal dynamics are interesting to capture in the light of cultural patterns dealing with status (both personal and professional) and participation in ruling one's increasingly diverse community. According to Lyotard (1984), the nature of knowledge has to change in the midst of all the alterations that affect society as a whole. Technology has restated the logical rules of interpersonal and artificial - human intelligence interactions based on what qualifies as "knowledge" statements. Under these circumstances, it would be interesting to determine how much technology (re)writes our organic history.

This is possible due to Lyotard's "mercantilization of knowledge" that defines new relationships between suppliers and users of gnosis following pragmatic, cost-efficiency-based patterns. Knowledge is produced and consumed to improve constantly the input-output relationship, as "...the goal is exchange" (Lyotard, 1984, p. 4). The new commodity is rapidly taking over world markets and re-establishing old spheres of influence based on emerging technology-driven/based economic interests. Those who initiate and control the flow of information, in spite of the ever increasing diversity in terms of content and form, subtly mandate or allocate "wavelengths" to be used by communicators. A new conformity managing the use of the same language games is brought into place to become the new norm. This is the point where Lyotard poses a set of fundamental ethical questions focusing on the initiators of such change, as well as with the individuals or groups to be kept informed throughout the whole process.

One essential aspect of postmodernity deals with social bonds and the influence of the knowledge - custom/tradition/(meta)narrative dichotomy on the transmission of scientific knowledge. In today's world, the self exists in a complex and flexible nexus of tight relations with the others, which have become a continuous multiplicity of the increasingly interchangeable "other." There may seem to be a contradiction in the interconnectedness of the individual and her/his replaceable nature within the social fabric. Each time someone enters the world, his/her petits récits are told through various set rites of passage. Such narratives coordinate one's evolution (Lyotard, 1984) to the point of matching the individual to a position that is available for anyone with her/his qualifications. Under these circumstances, we witness a weakening of social bonds (Lyotard, 1984). The isolated individual, though surrounded by family, neighbors, and acquaintances, is confused by the hollow reality of his/her identity within an ever changing social milieu. Consequently, the postmodern person feels the urge to enroll in an organization that would satisfy the need for belonging. Such a community could be based on diverse reasons ranging from political or professional affiliation to religious beliefs, leisure time interests or television show preferences, to name only a few possibilities. In the process of establishing oneself as a contributing member, each individual constantly re-creates his or her own history by re-telling/relating to those around, by sharing some parts of the private stories that the postmodern man writes daily as multi-personal tradition. Each social subject seems to be 
dissolved to be reborn each time in this dissemination of language games where social bonds are linguistic in nature, yet not held together by any single common core (Lyotard, 1984).

Considering the structure of social bond in postmodern society, popular culture is strongly linked with the relationship between knowledge and custom/tradition. Lyotard (1984) considers knowledge to rely on the interconnectedness of truth, efficiency, ethics, and aesthetics. The different attitudes, aptitudes, opinions, and sensibilities concur toward the (re)creation of postmodern culture. Yet, in a society that rejects consensus (though not in strategically important matters) for fear of the possibility of being accused of ignoring or breaking individual rights, dissemination of knowledge does not rely anymore on the distinction between tradition-bound and tradition-free individuals. They are all allowed to bring forth their unique personal narratives whose (dis)jointed ensemble should represent popular culture. In reality, this maelstrom does represent popular culture to the extent of reflecting the culture of the people, portraying them accurately. The subjects of this atomized society revolve around their petits récits, as they produce and acquire knowledge that, in turn, should promote them to a higher level of achievement, both professionally and personally. From this new station in life they can re-write their petits récits that, some day, may become the story behind a great name whose fame justifies the democratic, pluralistic nature of the society.

\section{Problem: Postmodern vs. modern education - points of (dis) juncture}

Since postmodernism resists labeling, rules and regulations, there could not be any set of prescriptions or strategies to be adopted by educators willing to distance themselves from the tradition of modernism. Discourse (i.e., negotiation) and praxis are the two main components of any postmodern approach to teaching and learning. Due to the diverse student and teacher body, differences have to be learned and celebrated as the foundation of society. Instructors and learners educate themselves while interacting formally in the school setting. This "trial and error" approach ensures the constant reshaping of the content to be learned as well as the context in which learning occurs. Students become aware of their individual role in bringing about the social change that supports the further development of society. This, in turn, is bound to challenge the educational arena by casting uncertainty over it, by resisting the comfort of the grands récits' explanatory and prescriptive familiarity and convenience. The most comprehensive outcome of this process integrates postmodernism into curriculum, without leading to a particular pattern in which a so-called postmodern curriculum is expected to unfold (Usher and Edwards, 1994).

Modernism presents educators as culturally disposed and "programmed" to disseminate knowledge. In this light, teaching relies heavily on the technical aspects of the profession, under the direct influence of the scientific method of defining truth, reason, and value in educational terms. Behaviorism supports this perspective on instruction. Categories of student behavior imply corresponding teaching strategies designed to ensure the achievement of the desired modification in behavior. This kind of knowledge delivery system ignores the affective domain that plays an important role in teaching and learning. Thus schools reproduce the existing social structure by introducing students to preset socially accepted 
authority figures and norms to be used within specified procedures distributing knowledge and social order.

Breaking away from such an approach means acknowledging that lifelong learning places both teachers and students on equal footing in the co-construction of knowledge. The shift in the role of (postmodern) educators derives from an emphasis on the process of learning as the dynamic synthesis of knowledge, skills, and dispositions that apply across various learning opportunities, irrespective of the learner's location (Usher and Edwards, 1994).

Authority/power and tradition, as previously passed down by school, cannot hold together anymore the foundational principles of a liberal education in a society that is faced with an increasing crisis in terms of a structuring authority and a sense-making tradition. A world whose meanings have become incomprehensible in their overwhelming diversity prefers to hold schools and educators accountable for any fault that, in fact, derives from the atomization of individual identities that cannot find a way back into the unifying mold of a pre-postmodern society. It seems that we try to make sense of petits récits by applying an all-encompassing grand récit pattern of analysis that stood the test of time, thus proving its validity and reliability. Power, mediated by knowledge, allows the individual to overcome, or at least become aware of his/her subjectivity. However, by doing so, he/she turns into a better, more productive subject who can see beyond his/her weaknesses, in an attempt to substantiate altruism. This is how one becomes less dependent on his/her self through training/instruction, yet increasingly relies on the social network that he/she wants to serve better by giving up subjectivity. According to traditional metanarratives, the postmodern individual takes knowledge as a way to acquire or preserve power. However, in a society where hyper-reality overlaps with one's physical milieu, knowledge can serve different purposes depending on its source, accessibility, and level of generalization, strongly linked with the concept of personal relevance. The information revolution, "the basis for a material break with modernity" (Peters, 1995, p. 123), gives the individual the chance to look for knowledge without anyone's prescription in the comfort of his home - "we live everywhere already in an 'aesthetic' hallucination of reality" (Baudrillard, 1983, p. 148).

\section{How to implement the postmodern curriculum in a modern classroom}

Since performativity is the prominent criterion in assessing all human pursuits in the postmodern world, education should assist individuals in becoming independent, productive citizens in a system featuring multifaceted identities. As a result, language games revolve around an inaccurate set of rights based on which anybody could have a word in contributing to the management of their respective community. Moreover, though postmodernism repudiates the traditional manner of transmitting knowledge and, consequently, of re-producing the power structure within the society, those in positions of power tend to feel more comfortable not giving up their status quo while being concealed by the pluralistic umbrella that embraces everything and everyone, and shields them from public questioning. The reproduction of discourses, values, and privileges has not been discontinued by accepting diversity. Differently put, multiculturalism was intended to bring to the forefront the petit récit of the "other," in an attempt to legitimize it while integrating it gradually into the larger 
discourses of the mainstream community. In actuality, the reproduction of the status quo has gone underground where it can gain momentum. Consequently, the voices of the "others" have become more diversified, yet the values that seem to govern everyone's life have been passed on rather tacitly, thus restricting the possibility for dialogue. The obvious outcome is that the status quo is no longer in danger of having to be compromised (or given up altogether), while its inherent privileges have become less conspicuous to the public eye.

If the postmodern curriculum is supposed to be the overarching principle holding together the diversity of individuals engaged in the co-construction of knowledge, skills, and dispositions, the whole idea of "status quo" bears significance on the ways in which this kind of curriculum gets designed, implemented, and evaluated. One example illustrating the perpetuation of the status quo - or the current conditions of the system, whether by the latter we mean schooling or the whole society - is offered by Eisner's analysis of the main factors influencing curricular work. First, the number of teachers who felt that their interests would be better defended in an institutionalized, partisan organization has increased constantly over the past decades from 71,000 in 1962 to $1,735,951$ in 1970, and then to 2,235,000 ten years later. "Unions and union-like organizations can become so preoccupied with the financial well-being of their members that in their efforts to achieve greater economic benefits the educational well-being of students suffers" (Eisner, 1985, p. 29). Second, "the public's demand to participate in educational policy formation and its demand that teachers and school administrators be held accountable finds expression in legislation requiring that pseudoscientific methods be used to appraise teaching and learning" (Eisner, 1985, p. 30). Third, the influence of textbooks based on which content-inclusion/exclusion policy is defined, as textbooks define the content, sequence, and aim of the curriculum. Finally, federal legislation and court decisions that "influence where people choose to live, what monies will be made available, what schools are obliged to teach, how schools will be populated, and where teachers will be asked to work" (Eisner, 1985, p. 37).

One possible interpretation of the data focuses exactly on the position teachers feel they have to take in order to defend themselves professionally. The discourse of principals and other decision makers in the field perpetuates power distribution. Thus, it increases the atomization of educators who need to unite their voices (and forces) to be taken into consideration. In addition, accountability raises the issue of professional safety that can be ensured by solidarity. All in all, it seems that values run differently for teachers, administrators, and students. The latter seem to have the most rights in the name of which the former two categories sometimes oppose their views. Analyzing the whole picture, status quo (the preservation of discourses, values and privileges) seems to be the cause for these certain factors that influence the field of curriculum and instruction.

Competence is a prerequisite to performativity. In this light, if one is to prove himself/herself "different" when it comes to competence (once again, a relative construct with a definite pragmatic role), his/her petit récit may not be included in the re-telling of personal stories that make up the constantly reforming tradition of the community. Diverse discourses speaking of difference may simply be produced without any chance to re-produce themselves. Their inherent values and rights/privileges are accepted as such, yet not 
professed. As a result, the competence of those in positions of power cannot be acquired, let alone replicated by the "others". Along the same lines, the former's values and privileges make front page every now and then in an attempt to present it as yet another story of personal achievement possible only in a pluralistic society. One may wonder what the "others" may gain from this kind of story-telling. They will strive to copy models that they read about, hear about, talk about in their adoration for a higher status rather than for a particular person.

Under such circumstances, schools try to meet the needs of every single student, teachers engage in research designed to answer the issue of teaching more efficiently, while students approach learning via the expected benefits it can get them - going to a top college, graduating with a "marketable" degree, landing a well-paid job, etc. In spite of our being diverse in our outlook and pluralistic in our intentions, we tend to aspire to the same reductionist model that has resisted many ideological/political currents and social regimes power has its masters and acolytes who exert it over the eternal "others".

In this light, it is quite interesting to determine the degree to which modern classrooms accommodate the postmodern curriculum whose diversity is ever increasing. As part of the author's personal experience in the college classroom, when asked about their expectations of a classroom setting today, an overwhelming majority of pre-service teachers enrolled in a general methods class at a Midwestern university pointed to rows of desk opposing the teacher's desk from where knowledge was expected to come. When asked about what would represent relevant content taught based on culturally appropriate pedagogical strategies, they all expressed the fact that the physical environment seemed to be less permissive than they would want it to be. Eventually, they all got to realize that there are a few inclusive, culturally sensitive ways in which to manage the actual classroom, while ensuring an adequate delivery of instruction. Yet, subsequent conversations with the same pre-service teachers revealed concerns about how to teach a postmodern, multicultural curriculum in a modern classroom while adhering to stricter accountability requirements in the field of education.

The postmodern individual moves back and forth between their contextual reality and the increasingly accessible hyper-reality that lures them with immediate gratification. The atomized society thrives on the eclectic mix of petits récits replacing the modern (and pre-modern) metanarratives. Pop culture figures have found their way into the classroom. Lifestyles are fluid and unpredictable. However, over all this reigns a set of standards and benchmarks spelling out accountability. In other words, an inclusive and dynamic organization (the modern classroom) supposes a flexible (postmodern) curriculum while observing an ever tightening structure (standards and benchmarks). Therefore, one may wonder whether or not the postmodern curriculum implies that educators can do anything under the auspices of accountability. If the academic content standards were pedagogically sound, they would align with the postmodern (atomized) nature of the curriculum. If the academic content was discriminatory/exclusionary, it would align better with the already filtered content included in standards and benchmarks. Provided all this reasoning is accurate, we may have a conflict of interests here. What would matter more is whose interests we are talking about - the "self" in a position of power or all the others who are represented by a few 
democratically-(s)elected "selves." Taking the conversation to a more generic level, what would postmodernism in education mean? It may represent a state of affairs leading to a style (artistically speaking or even in terms of a lifestyle) justified by a set of ideas (Ward, 2003). If postmodernism means a modus vivendi/operandi, does education reflect that in the classroom? Would the standards and benchmarks represent the modern metanarratives, while student characteristics prefigure the postmodern personal narratives (petits récits)?

As new cultural patterns are designed to aid the implementation of societal change, schools attempt to modify their curricula to capture the new trend. So what could come next? Is it possible that human language could have lost its referential power? Bertens (1995) defines postmodernism by acknowledging the "death of the author" (p. 7). Would that also imply the death of any possible referent that we could use to sequence our existence on a historic timeline? Are we to turn ourselves virtual in a world that is increasingly incapable to contain us anymore? As Durkheim (1972) puts it, we are in society and society is in us. The tension between the atomized individual trying to take in his/her society and this society's attempt to accommodate the individual is to be found in the gap between the modern classroom and the postmodern curriculum. In this light, how is the postmodern individual to gain and secure access to knowledge in a dynamic society? Considering that this Average Joe (or Jane) is increasingly alienated from the others (in spite of civic rights claims based on various affiliations with these others), the acquisition of knowledge could be used to exercise the power promised upon purchase of an education within the limitless frontiers of ... hyper-reality. Online education is to be brought to fruition in an offline reality. The online Average Joe (or Jane) is to redefine truth by using his (or her) knowledge to ascribe value to his (or her) petit récit. The just society we are trying to create relies on the civic engagement of all such Average Joes and Janes from all corners of our offline and online worlds. Yet, as the virtual world (or hyper-reality) seems to accommodate better the postmodern individual, local communities may become dangerously less and less their anchor in a superannuated reality.

The bridge between the modern classroom and the postmodern curriculum could be represented by investigating the possibilities of curriculum that account for how individuals (students and teachers) co-construct knowledge, based on which values are refined, gradually leading to re-defining truth through personal experience. Consequently, a curriculum of possibilities relies on two important applications of postmodern practice in the modern classroom: a) the centrality of reflection as what could be considered the zero degree of teaching, a point where the performative nature of instruction is informed by analyses of student learning; and b) the increasing use of self-assessment that leads to an awareness between being and becoming a valuable contributor to one's community. At the same time, curriculum is to be negotiated by teachers and students in an attempt to increase the relevance and applicability of learning by grounding it in personal and cultural codes (Leitch, 1996) that define positive school climate. The world of tomorrow may end up being less of an unknown to us today by ensuring that education is fundamentally dialogical (Slattery, 1995), thus representing a flexible social system relevant to the sustainability efforts currently undertaken. 


\section{References}

Baudrillard, J. (1983). Simulations. New York: Semiotext(e).

Bertens, H. (1995). The idea of the postmodern: A history. New York: Routledge. http://dx.doi.org/10.4324/9780203359327

Best, S., \& Kellener, D. (1997). The postmodern turn. New York: The Guilford Press.

Best, S., \& Kellner, D. (1991). Postmodern theory: Critical interrogations. New York: Guilford Press.

Calinescu, M. (1987). Five faces of modernity. Durham, NC: Duke University Press.

Durkheim, E. (1972). Selected writings. New York: Cambridge University Press.

Eisner, E. (1985). The educational imagination. ( $2^{\text {nd }}$ ed.). New York: Macmillan Publishing Company.

Eisner, E. (2001). Educating the "right" way: Markets, standards, God, and inequality. New York: RoutledgeFalmer.

Foucault, M. (1980). Power and knowledge: Selected interviews and other writings, 1972-1977. New York: Random House.

Giroux, H. (1992). Border crossings: Cultural workers and the politics of education. New York: Routledge.

Hyun, E. (2006.). Teachable moments: re-conceptualizing curriculum understandings. New York: Peter Lang Publishing.

Leitch, V.B. (1996). Postmodernism: Local effects, global flows. Albany, NY: State University of New York Press.

Lyotard, J.-F. ( 1984). The postmodern condition: A report on knowledge. Minneapolis, MN: University of Minnesota Press.

Peters, M. (Ed.). (1995). Education and the postmodern condition. Westport, CT: Bergin \& Garvey.

Peters, M. (Ed.). (1998). Naming the multiple: Poststructuralsim and education. Westport, CT: Bergin \& Garvey.

Ritzer, G. (2000). The McDonaldization of society. Thousand Oaks, CA: Pine Forge Press.

Slattery, P. (1995). Curriculum development in the postmodern era. New York: Garland Publishing, Inc.

Usher, R., \& Edwards, R. (Eds.). (1994). Postmodernism and education. London, UK: Routledge.

Ward, G. (2003). Postmodernism. Chicago, IL: McGraw-Hill. 


\section{Macrothink}

Wittgenstein, L. (1953). Philosophical investigations. New York: MacMillan.

\section{Copyright Disclaimer}

Copyright reserved by the author(s).

This article is an open-access article distributed under the terms and conditions of the Creative Commons Attribution license (http://creativecommons.org/licenses/by/3.0/). 